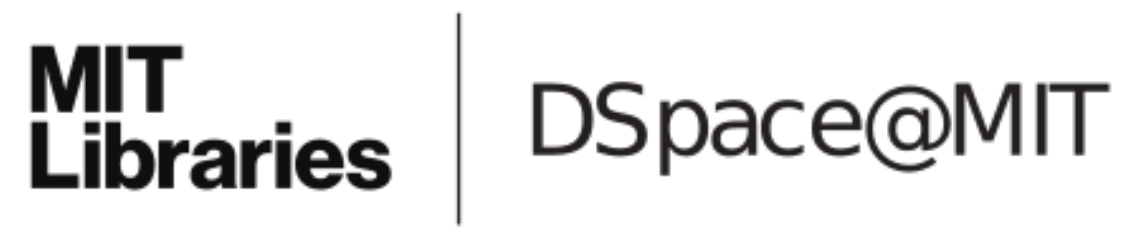

\author{
MIT Open Access Articles
}

Suspended Sediment Concentration

Profile in a Typha Latifolia Canopy

The MIT Faculty has made this article openly available. Please share how this access benefits you. Your story matters.

Citation: Xu, Y., \& Nepf, H. (2021). Suspended sediment concentration profile in a Typha Latifolia Canopy. Water Resources Research, 57, e2021WR029902.

As Published: http://dx.doi.org/10.1029/2021wr029902

Publisher: American Geophysical Union (AGU)

Persistent URL: https://hdl.handle.net/1721.1/140402

Version: Author's final manuscript: final author's manuscript post peer review, without publisher's formatting or copy editing

Terms of use: Creative Commons Attribution-Noncommercial-Share Alike 
Xu Yuan (Orcid ID: 0000-0001-6004-8119)

Nepf Heidi (Orcid ID: 0000-0002-3663-9071)

\title{
Suspended sediment concentration profile in a Typha latifolia canopy
}

\author{
Yuan $\mathrm{Xu}^{* 1,2}$ and Heidi Nepf ${ }^{2}$
}

1. State Key Laboratory of Hydroscience and Engineering, Tsinghua University, Beijing, China

2. Department of Civil and Environmental Engineering, MIT, Cambridge, MA, USA

*corresponding author, xuyuan18@mails.tsinghua.edu.cn

\section{Tey points}

Profiles of suspended sediment concentration (SSC) were measured in a model canopy of Typha latifolia.

The vertical turbulent diffusivity depends on plant-generated turbulence and morphology.

A model to predict vertical diffusivity was developed, validated, and used to simulate the SSC with a random displacement model.

This is the author manuscript accepted for publication and has undergone full peer review but has not been through the copyediting, typesetting, pagination and proofreading process, which may lead to differences between this version and the Version of Record. Please cite this article as doi: 10.1029/2021WR029902.

This article is protected by copyright. All rights reserved. 


\section{Abstract}

The transport of sediment in regions with vegetation plays an important role in aquatic ecosystems and landform evolution in river deltas. In this study, flow parameters and suspended sediment concentration (SSC) within an emergent canopy with real plant morphology (Typha latifolia) were measured in a laboratory channel. T. latifolia is a common marsh species with multiple thin leaves emerging from a tight bundle (culm) at the bed. The observed equilibrium SSC profile differed significantly from a Rouse profile, the classic model for SSC over bare beds. The vertical distribution of SSC was nearly uniform in the culm region of the canopy, and decreased with height in the upper canopy region of distributed leaves. The profile of SSC reflected the vertically-nonuniform turbulent diffusion, which arose from the plant morphology. A diffusivity model based on cylinder arrays was first validated with tracer data and then adapted to the T. latifolia morphology, providing a way to model turbulent diffusivity in marsh systems. The diffusivity model was successfully used within a random displacement model (RDM) to predict the spatial evolution and equilibrium SSC profile within the T. latifolia canopy.

\section{Introduction}

Aquatic vegetation provides important ecosystem services in rivers, lakes, wetlands, and coastal regions. It protects riverbanks and shorelines from floods and waves, provides shelter for aquatic organisms, enhances water quality, and promotes soil carbon accretion (e.g., Barbier et al., 2011; Costanza et al., 1997; Fourqurean et al., 2012; Kemp et al., 2000). During past decades, significant marsh and mangrove area has been lost from river deltas, diminishing these ecosystem services, so there is a growing interest in restoring and managing these systems (e.g., Mississippi River Delta and Mekong delta; Minderhoud et al., 2019; Nittrouer et al., 2012). To guide restoration, it is necessary to understand the interaction between flow, vegetation, and sediment transport. This study considers suspended sediment. In bare channels, the highest suspended sediment concentration (SSC) occurs at the bed, associated with bedgenerated turbulence and bed-shear stress (Jiménez, 2012). Turbulent diffusion carries sediment away from the bed (positive $z$ direction), until an equilibrium is reached between the upward diffusive flux and downward settling flux. This equilibrium is described by the Rouse profile, which has a maximum SSC at the bed (Coleman, 1986; Rouse, 1937). In an array of emergent cylinders, Lu (2008) found that the SSC profile was similar to that observed in a bare channel, decreasing from a maximum at the bed. By assuming a constant vertical diffusivity, Lu (2008) obtained an analytical solution for SSC, which agreed with their experimental data. Similarly, Huai et al. (2019) predicted the SSC profiles in the experiment of $\mathrm{Lu}$ (2008) assuming a uniform diffusivity in a random displacement model (RDM). The assumption of a vertically-uniform diffusivity is appropriate over most of the water depth within a uniform

This article is protected by copyright. All rights reserved. 
cylinder array (e.g., Lightbody \& Nepf, 2006; Nepf et al., 1997; Nepf, 1999). Tseng and Tinoco (2020) noted that the diffusivity is elevated in a thin boundary layer close to the bed and used this to develop a two-region model to predict the SSC profile in a cylinder array. However, real vegetation has a morphology distinct from uniform cylinders, which can produce significant vertical variation in velocity and turbulence (Tinoco, 2011; Xu \& Nepf, 2020; Zhang et al., 2021), which, in turn, will impact the SSC profile. For example, Li et al. (2020) observed a maximum SSC at the top of a submerged plastic canopy, not at the bed, and this was attributed to elevated turbulence, and thus diffusivity, associated with the shear-layer at the top of a submerged canopy. Similarly, Huai et al. (2019) predicted profiles of SSC measured with a submerged array of cylinders using a diffusivity model that represented the shear-layer turbulence. Vertical variation in emergent vegetation morphology will similarly impact the vertical distribution of turbulence, diffusivity, and SSC. Combining measurements and simulations of SSC, the present study considered these dependences for the marsh plant Typha latifolia, which has multiple thin leaves emerging from a tight culm at the bed (Figure 1).

\section{Methods}

\subsection{Experimental setup}

The experiments were conducted in a $24-\mathrm{m}$ long, $38-\mathrm{cm}$ wide recirculating flume with zero bed slope (Figure 1a). The model plant, Typha latifolia, consisted of long sword-shaped leaves, which were bundled into a culm at the base (Figure 1b). Each plastic plant consisted of 40 leaves, with lengths $l_{1}=30$ to $40 \mathrm{~cm}$ and widths $w_{1}=0.1$ to $0.4 \mathrm{~cm}$, which was the same as real T. latifolia leaves (Liu et al., 2017). The plants were placed in a staggered arrangement in PVC baseboards (Figure 1b). Once installed, the canopy height was $38 \pm 2 \mathrm{~cm}$. The length $(L)$ and width $(W)$ of the canopy was $16 \mathrm{~m}$ and $0.38 \mathrm{~m}$, respectively. The area density, $m$, was 119 plants $/ \mathrm{m}^{2}$, and the depth-average solid volume fraction $\phi=0.0057$ to 0.0065 , depending on depth. Plant characteristics are shown in Table 1. Importantly, unlike a cylinder array, the T. latifolia canopy was vertically non-uniform. Figure $1 \mathrm{c}$ shows the vertical profiles of plant frontal area per $\mathrm{cm}$ vertical interval, A $\left(\mathrm{cm}^{2} / \mathrm{cm}\right)$, which displays the vertical non-uniformity of $T$. latifolia. Due to this non-uniformity, the depth-average frontal area per volume $\langle a\rangle_{z}=m A_{f} / H$, in which $A_{f}$ is the cumulative frontal area of one plant, $A_{f}=\int_{0}^{H} A d z$, varied with water depth (Table 1).

Figure 1. (a) Side view of channel. Not to scale. Flow is left to right, with $x=0$ at leading edge of canopy, which was $16 \mathrm{~m}$ long. Particles were released from a nozzle upstream of the canopy. Velocity was measured with an ADV. SSC was measured with four optical backscatter sensors (OBS), mounted in pairs on two vertical rods. (b) Photo of T. latifolia canopy. (c) T. latifolia frontal area per $\mathrm{cm}$ vertical interval, $A\left(\mathrm{~cm}^{2} / \mathrm{cm}\right)$ (from Xu \& Nepf, 2020).

This article is protected by copyright. All rights reserved. 
The inlet to the channel was located $2 \mathrm{~m}$ upstream of the canopy, and flow was controlled by a variable speed pump. The flow rate was monitored by an electromagnetic flowmeter mounted on the return pipe. The instantaneous velocity $(u, v, w)$, corresponding to $x$ (longitudinal), $y$ (lateral), and $z$ (vertical) directions, respectively, was recorded using a Nortek Vectrino Acoustic Doppler Velocimeter (ADV). Spikes in the velocity record were removed by a MATLAB code, which used the acceleration threshold method described in Goring and Nikora (2002). Vertical profiles were measured with a resolution of $1 \mathrm{~cm}$. Four lateral positions between plant rows were chosen to capture the lateral variation within the canopy. The measurements were first time-averaged, denoted by an overbar, then laterally-averaged, denoted by \langle\rangle , and finally depth-averaged, denoted by \langle\rangle$_{z}$. Additional details for the velocity measurements can be found in Section 3.3.1 in Xu and Nepf (2020). The velocity was measured at $x=8 \mathrm{~m}$ (i.e., mid-length along the canopy, Figure 1a). Based on a previous study with the same canopy, the velocity and turbulence were fully developed at $0.58 \mathrm{~m}$ from the leading edge. Three water depths $(H=20,30$, and $35 \mathrm{~cm})$ were considered (Table 1). For each water depth, three to four different flow discharges were chosen, producing ten cases. The channelaverage velocity $U$ ranged from 4.8 to $18.5 \mathrm{~cm} / \mathrm{s}$, which was consistent with values measured in the field (e.g., Leonard \& Luther, 1995; Naden et al., 2006). Plant reconfiguration (bending) was not considered, and for the flow and depth conditions considered here, the model plants did not reconfigure (see discussion in section 4.5 of Xu \& Nepf, 2020). The water surface slope, $S$, was measured with two wave gauges with $0.2 \mathrm{~mm}$ accuracy and $1000 \mathrm{~Hz}$ sampling rate, which were located at $x=0.5 \mathrm{~m}$ and $14.5 \mathrm{~m}$ (Table 1, and Supporting Information).

Table 1. Summary of experiment conditions and best-fit diffusion scale factor

\begin{tabular}{cccccccc}
\hline Run & $\begin{array}{c}\mathrm{H} \\
(\mathrm{cm})\end{array}$ & $\begin{array}{c}U \pm \sigma_{U}{ }^{a} \\
(\mathrm{~cm} / \mathrm{s})\end{array}$ & $\begin{array}{c}\langle a\rangle_{z}{ }^{b} \\
\left(\mathrm{~m}^{-1}\right)\end{array}$ & $\phi$ & $\begin{array}{c}x \text {-location of SSC measurements } \\
(\mathrm{m})\end{array}$ & $\begin{array}{c}S \pm \sigma_{S}{ }^{c} \\
\left(10^{-3}\right)\end{array}$ & $\begin{array}{c}\text { Best-fit } \alpha_{z} \\
\text { at equilibrium }\end{array}$ \\
\hline 1.1 & 20 & $7.6 \pm 0.3$ & 3.10 & 0.0057 & $1.0,3.1,13.2,14.1$ & $1.3 \pm 0.1$ & 2.5 \\
1.2 & 20 & $9.4 \pm 0.5$ & 3.10 & 0.0057 & $0.5,1.0,1.9,3.1,13.2,14.1$ & $1.6 \pm 0.1$ & 2.0 \\
1.3 & 20 & $13.1 \pm 0.6$ & 3.10 & 0.0057 & $13.2,14.1$ & $3.6 \pm 0.3$ & 2.0 \\
1.4 & 20 & $18.5 \pm 1.1$ & 3.10 & 0.0057 & $13.2,14.1$ & $7.7 \pm 0.5$ & 1.5 \\
2.1 & 30 & $6.4 \pm 0.3$ & 3.85 & 0.0064 & $13.2,14.1$ & $1.2 \pm 0.1$ & 4.0 \\
2.2 & 30 & $9.4 \pm 0.5$ & 3.85 & 0.0064 & $0.5,1.0,1.9,3.1,13.2,14.1$ & $2.9 \pm 0.2$ & 3.0 \\
2.3 & 30 & $13.9 \pm 0.6$ & 3.85 & 0.0064 & $13.2,14.1$ & $5.6 \pm 0.5$ & 2.5 \\
3.1 & 35 & $4.8 \pm 0.2$ & 3.94 & 0.0065 & $13.2,14.1$ & $0.8 \pm 0.1$ & 3.0 \\
3.2 & 35 & $7.6 \pm 0.4$ & 3.94 & 0.0065 & $1.0,3.1,13.2,14.1$ & $1.9 \pm 0.2$ & 3.5 \\
3.3 & 35 & $11.4 \pm 0.5$ & 3.94 & 0.0065 & $13.2,14.1$ & $3.3 \pm 0.2$ & 3.0 \\
\hline
\end{tabular}

This article is protected by copyright. All rights reserved. 
${ }^{a}$ Channel-average velocity $U$ determined from the flowmeter was equal to the velocity $\langle\bar{u}\rangle_{z}$ measured with the ADV. The uncertainty $\sigma_{U}$ was associated with fluctuations in the flowmeter reading. ${ }^{\mathrm{b}}$ Depth-average frontal area per volume $\langle a\rangle_{z}=m A_{f} / H . A_{f}$ is the cumulative frontal area of one plant, $A_{f}=\int_{0}^{H} A d z .{ }^{\mathrm{c}}$ Uncertainty in slope $\sigma_{s}$ arose from fluctuations of water surface.

The model sediment consisted of silica particles with density $\rho_{s}=2.5 \mathrm{~g} / \mathrm{cm}^{3}$ and median diameter $D_{50}=29 \mu \mathrm{m}$ (Potters Industries, Valley Forge, PA). The particle size was chosen to ensure that the sediment could be suspended within the range of possible flow conditions. The particle size distribution (Figure S2 in Supporting Information) was measured using a Beckman Coulter laser diffraction instrument (Follett \& Nepf, 2018). The settling velocity, $w_{s}$, was estimated using Eqn. 4 in Ferguson and Church (2004). For $D_{50}=29 \mu \mathrm{m}, w_{s 50}=0.067 \mathrm{~cm} / \mathrm{s}$ (Supporting Information). Particles were released at mid-depth and slightly upstream of the canopy, at $x=-0.15 \mathrm{~m}$ (Figure 1a). Before each experiment, $700 \mathrm{~g}$ of particles were mixed with $10 \mathrm{~L}$ water to form a dilute solution. The particle slurry was continuously mixed in a 15 -L bucket using a magnetic stirrer and injected continuously through a 2-mm nozzle using a peristaltic pump (Figure 1a). A tee-shaped nozzle directed the slurry in the $\pm y$ direction. The slurry discharge rate, $Q_{i n}$ was $12.6 \pm 1.9 \mathrm{ml} / \mathrm{s}$.

The suspended sediment concentration was measured using four optical backscatter sensors (OBS, Seapoint Sensors Inc.). A prepared slurry concentration, ranging from $0-500 \mathrm{mg} / \mathrm{L}$, was used to calibrate the OBS output voltage with concentration (see Supporting Information). Pairs of OBSs were mounted on a thin rigid rod (Figure 1a), which moved vertically. SSC was measured simultaneously at two longitudinal positions. A preliminary test experiment was conducted for each flow condition to determine the time at which stationary SSC conditions were reached (Figure S4 in Supporting Information). The OBS measurement began when the particle release began and measured continuously at $20 \mathrm{~Hz}$ for the entire duration of the release $(12 \mathrm{~min})$. This time allowed particles to recirculate in the flume at least twice. The SCC record revealed the time period of steady state SSC conditions. In subsequent runs with the same flow conditions, the vertical profile of SSC was measured within the steady time-period by vertically moving the rigid rod to obtain measurements at eight vertical positions. Each case was repeated to assess method uncertainty. To observe the longitudinal evolution of SSC, multiple experiments were conducted for the same flow condition, with the OBS at different streamwise positions (Table 1).

Fine particles can be captured directly by plant leaves, and other plant surfaces (Kretz et al., 2020). This on-plant sedimentation decreases with increasing flow velocity or collector Reynolds number (Fauria et al., 2015; Purich, 2006; Wingenroth et al., 2021). At the leaf scale, Kretz et al. (2019) observed that adaxial pubescence and enhanced sedimentation on leaves. However, for the flow conditions (relatively high flow velocity), plant characteristics (low

This article is protected by copyright. All rights reserved. 
canopy density and smooth leaves without pubescence), and absence of biofilm in present study, the on-plant sedimentation was negligible. This was confirmed by the fact that the measured flux of particles in the water column agreed with the injected flux, indicating that deposition of any sort (to the bed or to the plant surfaces) was small enough to be neglected in the experiments.

\subsection{Random displacement model}

A 2D (streamwise, $x$, and vertical, $z$ ) random displacement model was used to simulate the transport of individual particles. Within each time-step, $\Delta t$, particles were displaced by time-mean advection in $x$ and turbulent diffusion in $z$ (Gardiner, 1985). Assuming a high streamwise Peclet number, the longitudinal diffusion was neglected (Taylor, 1953). The particle position at time step $i+1$ was described as in Tsai et al. (2020):

$$
\begin{gathered}
x_{i+1}=x_{i}+\left\langle\bar{u}\left(z_{i}\right)\right\rangle \Delta t \\
z_{i+1}=z_{i}+\left(\frac{\partial K_{z}}{\partial z}\left(z_{i}\right)-w_{s}\right) \Delta t+\sqrt{2 K_{z}\left(z_{i}\right) \Delta t} R
\end{gathered}
$$

in which $K_{z}$ is the sediment diffusivity in $z$. The term $\partial K_{z} / \partial z$ is a pseudo-velocity needed to prevent the artificial accumulation of particles in the regions of low diffusivity (Durbin, 1983; Wilson \& Yee, 2007). $R$ is a random variable with standard Gaussian distribution (zero mean and unit variance). In this study, sediment diffusivity $K_{z}$ was assumed equal to turbulent diffusivity $D_{z}$, since the particles were fine enough for this assumption (Absi, 2010).

The time-step, $\Delta t$, was chosen so that the vertical particle trajectory within each time-step was much smaller than the scale of vertical gradients in the diffusivity and velocity (Follett et al., 2016; Israelsson et al., 2006). Huai et al. (2019) suggested the length scale $0.05 H$ for emergent vegetation.

$$
\Delta t<\min \left(\frac{0.05 H}{\left|\frac{\partial D_{Z}}{\partial z}-w_{s}\right|_{\max }}, \frac{(0.05 H)^{2}}{\left(D_{Z}\right)_{\max }}\right)
$$

Simulations with different $\Delta t$, ranging from $0.01 \mathrm{~s}$ to $0.1 \mathrm{~s}$, confirmed that the solution was insensitive to time step within this range (varied by less than $5 \%$ ). The time-step was set as $0.05 \mathrm{~s}$.

The measured flux of suspended particles within the canopy, $\left(\langle C\rangle_{z} \cdot W \cdot H \cdot U\right)$, agreed with the injected flux $\left(C_{i n} Q_{i n}\right)$ to within $10 \%$. This confirmed that no deposition occurred. This was represented in the RDM using a no-flux (reflecting) boundary condition at the channel bottom. The same boundary condition was applied at the water surface, because particles cannot pass through or collect at the surface (Huai et al., 2019; Murphy, 2006):

$$
\begin{array}{lr}
z_{i}=-z_{i}, \quad z_{i}<0 & \text { (bottom boundary) } \\
z_{i}=2 H-z_{i}, \quad z_{i}>H & \text { (water surface) }
\end{array}
$$

Within the RDM 10,000 particles were released at the same point that particles entered the canopy in the experiment, 
and the RDM was run for 6000 steps $(300 \mathrm{~s}, \Delta t=0.05 \mathrm{~s})$, which simulated the duration of the physical experiment. Comparison of SSC profiles simulated with $D_{50}$ and with a distribution of sizes suggested that $D_{50}$ was a good representative size (Figure S5 in Supporting Information). Each simulation was repeated for 10 realizations.

To translate the discrete particle positions into a concentration profile, the water depth was divided into $N=50$ layers, and the concentration, $C$, was calculated as the number of particles per layer height.

The adaption time, $T_{a}$, describes the time-scale needed to reach an equilibrium profile of concentration, defined by the balance of upward diffusion and downward settling. Equilibrium was reached in the RDM when the vertical profile of concentration changes by less than $2 \%$ between time-steps. Specifically, the mean percentage error (MPE) summed over the 50 vertical positions was calculated between the current $i$ and previous $i-1$ time-step,

$$
\operatorname{MPE}(i)=\frac{\sum_{j=1}^{N} \frac{\left|c_{j}(i-1)-C_{j}(i)\right|}{C_{j}(i)}}{N} \times 100 \%
$$

in which $C_{j}(i)$ is the sediment concentration in $j^{\text {th }}$ layer at the $i^{\text {th }}$ time step. The adaption time, $T_{a}$, was defined at the time-point when MPE was less than 2\%.

\subsection{Parameterization of Transport Parameters in Typha latifolia}

The RDM was run with the measured velocity profile $\langle\bar{u}\rangle$ and a turbulent diffusion based on the model of Tanino and Nepf (2008). Turbulent diffusivity can be described in terms of a turbulent velocity $\left(\sqrt{k_{t}}\right)$ and length-scale $\left(l_{t}\right)$,

$$
D=\alpha \sqrt{k_{t}} l_{t}
$$

in which $l_{t}$ is the integral length-scale, $k_{t}$ is the turbulent kinetic energy (TKE) per fluid mass, and $\alpha$ is a scale constant. Within a canopy, $l_{t}, k_{t}$, and $\alpha$ are shaped by vegetation-generated turbulence (e.g., Nepf, 2012). Models for $\alpha, l_{t}$ and $k_{t}$ have been developed and validated for an array of rigid, circular cylinders (Tanino \& Nepf, 2008). For the $T$. latifolia canopy, $l_{t}$ equals the culm diameter, $d$, near the bed and the leaf width, $w$ near the surface, with a smooth transition between (see Eqn. 16 in Xu \& Nepf, 2020, repeated here for convenience).

$$
l_{t}=\left\{\begin{array}{cc}
d=1.5, & z<10 \\
3.6-0.19 z, & 10 \leq z<17 \\
w=0.2 & z \geq 17
\end{array}\right.
$$

All units in Eqn. 8 are in $\mathrm{cm}$. Note that this relationship represents the average profile measured over many water depths. The turbulent kinetic energy $k_{t}$ also varies over the T. latifolia canopy height (see Eqn. 17 in Xu and Nepf, 2020),

$$
k_{t}(z)=\gamma^{2}\left(C_{D} \frac{a l_{t}}{2(1-\phi(z))}\right)^{2 / 3}\langle\bar{u}\rangle^{2}
$$

in which the frontal area per canopy volume $(a$, Figure $1 \mathrm{c})$, solid volume fraction $(\phi)$, and velocity, $\langle\bar{u}\rangle$, are all

This article is protected by copyright. All rights reserved. 
functions of $z$. Strictly, Eqn. 9 should use the form drag coefficient $\left(C_{D}{ }^{\text {form }}\right.$, Tanino \& Nepf, 2008). However, at typical Reynolds numbers in a canopy, the viscous drag is small compared to the form drag, and $C_{D}{ }^{\text {form }} \approx 0.9 C_{D}$ (for plant element $R e>200$, Etminan et al., 2018), making it reasonable to simplify Eqn. 9 using $C_{D} \approx C_{D}{ }^{\text {form }}$. The scale coefficient for T. latifolia, $\gamma^{2}=1.6 \pm 0.4$ (Xu \& Nepf, 2020), is slightly larger than that determined for an array of rigid cylinders $\left(\gamma^{2}=1.1 \pm 0.2\right.$, Eqn. 3.33 in Tanino, 2008), suggesting that $\gamma^{2}$ may be sensitive to the plant morphology. The present study considered whether predictions of $l_{t}$ and $k_{t}$ from Eqns. 8 and 9 could be used in Eqn. 7 to predict the turbulent diffusivity within a T. latifolia canopy.

For a canopy of cylinders with diameter $d$ and the marsh-relevant solid volume fraction $\phi<0.03$, the mixing length-scale $l_{t}=d$, and $\alpha$ depends on both $\phi$ and the cylinder arrangement (random versus regular array, Tanino $\&$ Nepf, 2008). In particular, $\alpha$ reflects the fraction of canopy space in which the local center-to-center spacing $s_{n c}$ between cylinders is more than $2 d, P_{s_{n c}>2 d}$, because only these regions can support eddies $l_{t}=d$. For a random array $P_{s_{n c}>2 d}=f(\phi)$, but for a staggered or square array in this range, $P_{s_{n c}>2 d}=1$. Note that Tanino and Nepf (2008) considered lateral diffusivity, which we note with subscript $y$. The function $\alpha_{y}=F(\phi)$, based on Eqn. 2.16 and Appendix A in Tanino and Nepf (2008), is shown in Figure 2. Additional details are provided in Section S7 in the Supporting Information. Within a cylinder array, measured vertical diffusivity has been shown to be smaller than lateral diffusivity, $D_{z} \approx 0.25 D_{y}$ for $\phi=0.006$ to 0.053 (Nepf et al., 1997), which is consistent with the vertical orientation of the array elements. However, field measurements show $D_{z} \approx D_{y}$ in Spartina alterniflora, which has a morphology similar to T. latifolia (Lightbody \& Nepf, 2006; Tarrell, 1997). The isotropic diffusion was attributed to the varied orientation of real plant elements.

Figure 2. Diffusivity scale constant $\alpha_{y}=D_{y} / \sqrt{k_{t}} d$ for lateral turbulent diffusion in an array of cylinders with diameter, $d$, based on Eqn. 2.16 and Appendix A in Tanino and Nepf (2008). Solid curve is a regular array with $P_{s n c>2 d}=1$. Dashed curve is for a random array with $P_{s n c>2 d}$ described in Eqn. A21 in Tanino and Nepf (2008). Vertical gray bar indicates the T. latifolia canopy in this study, with $\phi=0.0057$ to 0.0065 , Table 1 .

\section{Results and discussion}

\subsection{Validation of vertical diffusivity model}

\subsubsection{Transport of a neutrally buoyant tracer in a cylinder array}

To validate the diffusivity model (Eqns. 7, 8, and 9) and the RDM method, the model was used to simulate a laboratory experiment that measured dye transport (Rhodamine WT) in a cylinder array consisting of two layers of different cylinder density (Lightbody \& Nepf, 2006). The dye was dilute enough to be neutrally buoyant, so that $w_{s}=0$ in

This article is protected by copyright. All rights reserved. 
Eqn. 2. Cylinders with diameter $d=0.64 \mathrm{~cm}$ and two lengths were arranged randomly in a predrilled plastic sheet, creating a canopy with two layers: a sparser lower layer with $m_{1}=300 \mathrm{stems} / \mathrm{m}^{2}$ and $\phi=0.0097$, and a denser upper layer with $m_{2}=600$ stems $/ \mathrm{m}^{2}$ and $\phi=0.0193$ (Figure 4-10 in Lightbody, 2004). The dye was released at mid-width and $0.5 \mathrm{~cm}$ from the channel bed. Velocity and dye concentration were measured using an ADV and a Rhodamine fluorometer, respectively. Vertical diffusivity $D_{z}$ was determined in their study by fitting measured concentration profiles to analytical solutions for vertical concentration profiles (Table 2, the third column).

Table 2. Flow characteristics in Lightbody (2004)

\begin{tabular}{ccccccc}
\hline \multirow{2}{*}{$H(\mathrm{~cm})$} & \multicolumn{2}{c}{$U(\mathrm{~cm} / \mathrm{s})$} & \multicolumn{2}{c}{ Measured } & $D_{z}\left(\mathrm{~cm}^{2} / \mathrm{s}\right)$ & \multicolumn{2}{c}{ Predicted $D_{z}$} & from Eqn.7 \\
\cline { 2 - 7 } & Lower layer & Upper layer & Lower layer & Upper layer & Lower layer & Upper layer \\
\hline $20 \pm 1$ & $5.2 \pm 0.1$ & $3.4 \pm 0.1$ & $0.25 \pm 0.16$ & $0.04 \pm 0.08$ & $0.24 \pm 0.08$ & $0.09 \pm 0.04$ \\
\hline
\end{tabular}

Based on the Tanino model for a random cylinder array $\alpha_{y}=0.90$ and 0.77 for $\phi=0.0097$ and $\phi=0.0193$, respectively. For a cylinder array, we expect $\alpha_{z}=0.25 \alpha_{y}$, yielding $\alpha_{z}=0.23$ and 0.19 , respectively. Using these scale factors, the measured $k_{t}$, and $l_{t}=d$ in Eqn. 7, the vertical diffusivity $D_{z}$ was predicted to be $0.24 \pm 0.08 \mathrm{~cm}^{2} / \mathrm{s}$ for lower layer and $0.09 \pm 0.04 \mathrm{~cm}^{2} / \mathrm{s}$ for upper layer, which agreed with the measured diffusivity within uncertainty (Table 2). Further, this diffusivity accurately predicted the measured concentration profiles. Specifically, 10000 particles were released at $0.5 \mathrm{~cm}$ from the simulated bed, consistent with the experimental setup, and the simulation was run until steady-state was achieved at four distances from the release $(x=50,100,200$, and $300 \mathrm{~cm})$. The simulation was run 10 times to provide an assessment of random error. At each longitudinal position, the ensemble average concentration from the 10 realizations agreed with the measured concentration to within less than $7.5 \%$, which validated the vertical diffusivity model for a canopy of cylinders (Figure 3a).

Figure 3. (a) Simulated concentration (dashed lines) and measured concentration (symbols, from Lightbody, 2004). The vertical coordinate was normalized by water depth, $H$, and the concentration was normalized by $C_{a}$, the reference concentration at $z=0.1 \mathrm{H}$. Standard error among ten realizations ranged from $1 \%$ to $4 \%$. The gray dashed line denotes the interface between two layers. At each position the simulated concentration agreed with the measured concentration to within $7.5 \%$ (b) Comparison of equilibrium SSC profile simulated with RDM and measured by $\mathrm{Lu}$ (2008). The gray area denotes the uncertainty of RDM results. $C_{a}$ is the reference concentration at $z=0.5 H$.

\subsubsection{Transport of suspended sediment in a cylinder array}

The diffusivity model and RDM method were also validated for sediment transport using data from Lu (2008), who measured suspended sediment concentration in a square array of circular cylinders with diameter $d=0.6 \mathrm{~cm}$ and solid

This article is protected by copyright. All rights reserved. 
volume fraction $\phi=0.028$. The plastic particles were $217 \mu \mathrm{m}$ with $w_{s}=0.162 \mathrm{~cm} / \mathrm{s}$. Lu et al. (2008) circulated the particles long enough to obtain an equilibrium SSC profile. They measured velocity and concentration using an ADV and a siphon, respectively. The velocity was vertically uniform, as expected for a uniform cylinder array (Figure 6-7 in $\mathrm{Lu}, 2008)$.

Table 3. Flow and canopy characteristic in $\mathrm{Lu}(2008)$

\begin{tabular}{cccccccc}
\hline Case & $H(\mathrm{~cm})$ & $U(\mathrm{~cm} / \mathrm{s})$ & $\phi$ & $S\left(10^{-3}\right)$ & $k_{t}\left(\mathrm{~cm}^{2} / \mathrm{s}^{2}\right)$ & $\alpha_{z}$ & $D_{z}\left(\mathrm{~cm}^{2} / \mathrm{s}\right)$ \\
\hline $\mathrm{D} 18-3$ & 18.0 & 16.9 & 0.028 & 13.6 & $19.9 \pm 3.8$ & 0.65 & $1.7 \pm 0.3$ \\
\hline
\end{tabular}

The turbulent kinetic energy, $k_{t}=19.9 \pm 3.8 \mathrm{~cm}^{2} / \mathrm{s}^{2}$, was determined from measured velocity and Eqn. 9 . For a square array with $\phi=0.028, \alpha_{y}=2.6$ (Figure 2), and within a cylinder array we expect $\alpha_{z}=0.25 \alpha_{y}=0.65$. From these estimates, Eqn. 7 predicted the turbulent diffusion $D_{z}=1.7 \pm 0.3 \mathrm{~cm}^{2} / \mathrm{s}$ (standard error propagated from TKE prediction). The equilibrium SSC profile simulated using this predicted diffusivity agreed with the measured profile to within the uncertainty (based on standard error among 10 realizations of RDM, gray area in Figure $3 b$ ), indicating that the diffusivity prediction (Eqn. 7) and RDM method had good performance simulating suspended sediment transport. In conclusion, results presented in this section have validated the vertical diffusivity model for cylinder arrays (Eqns. 7, 8,9) with both neutrally-buoyant tracer and sediment. However, the extension of this model to more complex morphology must still be considered, which is the goal of the remainder of this paper.

\subsection{Measured SSC profiles in Typha latifolia canopy}

The concentration profiles measured at $x=13.2 \mathrm{~m}$ and $14.1 \mathrm{~m}$ (open and filled symbols, respectively, Figure 4a) differed by less than $6 \%$, which was comparable to the uncertainty, indicating that the SSC has reached the equilibrium profile by this point. For further analysis, the SSC at these two positions were averaged to represent the equilibrium profiles, which are presented for flow depths $H=20 \mathrm{~cm}$ and $35 \mathrm{~cm}$ in Figure $4 \mathrm{~b}$ and $4 \mathrm{c}$, respectively. For comparison, the profile predicted for a bare channel with the same velocity (Rouse profile) was plotted with dashed curves. For the bare channel, the vertical turbulent diffusion has a parabolic distribution (e.g., Cellino, 1998):

$$
D_{z}=\kappa u_{*} z\left(1-\frac{z}{H}\right)
$$

in which $\kappa(=0.4)$ is the von Karman constant and $u_{*}$ is the friction velocity, estimated from the linear distribution of Reynolds stress in the bare channel. For the same channel velocity and depth, SSC profiles in the T. latifolia (symbols) differed significantly from the Rouse profile. Within the T. latifolia, SSC was close to vertically uniform in the lower culm region $(z<15 \mathrm{~cm}$ ), which corresponded to nearly the full flow depth for $H=20 \mathrm{~cm}$ (Figure $4 \mathrm{~b}$ ).

This article is protected by copyright. All rights reserved. 
With greater water depth $(H=35 \mathrm{~cm}$, Figure $4 \mathrm{c})$, SCC decreased with distance from the bed in the upper region of the canopy $(z>15 \mathrm{~cm})$. A more uniform SSC profile in the T. latifolia, compared to bare channel, can be attributed to vegetation-induced turbulence, which increased turbulence intensity by nearly seven-fold, relative to a bare channel with same channel-average velocity (Figure 4e). Further, the shape of the SCC profile can be correlated with vertical variation in $k_{t}$ and $l_{t}$ (Figure $4 \mathrm{e}$ and $\left.4 \mathrm{f}\right)$. Specifically, $l_{t}$ was higher in the lower canopy $(z<15 \mathrm{~cm})$, where turbulence length-scale was set by the culm diameter, compared to the upper canopy (z $>15 \mathrm{~cm})$, where $l_{t}$ was set by the leaf width. Similarly, $k_{t}$ was higher in the lower canopy $(z<15 \mathrm{~cm})$, where the local velocity was higher (Figure 4d). Higher values of $k_{t}$ and $l_{t}$ in the lower canopy would be associated with higher values of turbulent diffusivity (Eqn. 7), which was consistent with a more uniform SSC in the lower region of the canopy, compared to the upper canopy (Figure 4c).

Figure 4. (a) SSC within T. latifolia canopy at $x=13.2 \mathrm{~m}$ (open symbols) and $14.1 \mathrm{~m}$ (filled symbols) for Case 1.1 (circles, $H=20 \mathrm{~cm}, U=7.6 \mathrm{~cm} / \mathrm{s}$ ) and Case 3.2 (diamonds, $H=35 \mathrm{~cm}, U=7.6 \mathrm{~cm} / \mathrm{s}$ ). Subplots (b) and (c) show equilibrium SSC profiles in T. latifolia for (b) $H=20 \mathrm{~cm}$ and (c) $H=35 \mathrm{~cm}$. The dashed lines show the SSC profile in bare channel estimated with Rouse formula. (d) measured values of velocity, $\langle\bar{u}\rangle$, and (e) measured TKE, $\left\langle k_{t}\right\rangle$, each normalized by the channel average velocity $U$, and (f) integral length-scale, $l_{t}$ for Case 3.1 , with $H=35 \mathrm{~cm}$ Open triangles represent the bare channel with the same flow condition (legend in subplot d).

The vertical distribution for SSC became more uniform as the channel-average velocity increased (Figure 4c). Specifically, the bed to surface concentration difference decreased from 0.71 to 0.36 as velocity increased from 4.8 $\mathrm{cm} / \mathrm{s}$ (blue dots, Case 3.1) to $11.4 \mathrm{~cm} / \mathrm{s}$ (red dots, Case 3.3). This suggested that vertical diffusivity increased with velocity, which was consistent with the scaling $D_{t} \sim \sqrt{k_{t}} \sim U$. For $H=20 \mathrm{~cm}$, a velocity dependence was not observed (Figure 4b), because in each of these cases the diffusivity was high enough to produce an essentially uniform SSC profile. For example, the depth-average diffusivity, $\left\langle D_{z}\right\rangle_{z}=5.6 \mathrm{~cm}^{2} / \mathrm{s}$, for Case 1.1 was higher than the value, $\left\langle D_{z}\right\rangle_{z}=2.9 \mathrm{~cm}^{2} / \mathrm{s}$, for Case 3.1. Furthermore, the diffusivity profile was much more uniform over depth for $H=20 \mathrm{~cm}$ (Case 1.1, Figure 6b) than for $H=35 \mathrm{~cm}$ (Case 3.1, Figure 6d).

\subsection{Canopy drag coefficient}

The T. latifolia drag coefficient, $C_{D}$, is needed to predict $k_{t}$ and thus turbulent diffusivity (Eqns. 7 and 9). The drag coefficient was estimated from the momentum balance and measured water surface slope $S$ (Table 1). In sparse, emergent canopies, viscous, Reynolds, and dispersive stresses are typically much smaller than canopy drag (Lightbody \& Nepf, 2006; Xu \& Nepf, 2020), so that the momentum equation for fully-developed, steady flow can

This article is protected by copyright. All rights reserved. 
be simplified to a balance of canopy drag and pressure.

$$
0=\underbrace{g S}_{\begin{array}{c}
\text { pressure } \\
\text { forcing term }
\end{array}}-\underbrace{\frac{1}{2} \frac{C_{D} a}{(1-\phi)} U^{2}}_{\begin{array}{c}
\text { vegetation } \\
\text { drag }
\end{array}}
$$

Xu and Nepf (2020) determined a drag coefficient for an individual plant using a force transducer to measure the drag on an individual plant within a canopy. To explore whether this plant-scale drag coefficient represents the distributed drag within a canopy (canopy-scale drag coefficient, based on Eqn. 11), $C_{D}$ estimated by the two methods are compared in Figure 5. The plant-scale $C_{D}$ agreed with the canopy-scale $C_{D}$ to within $10 \%$, and $C_{D}$ (plant-scale) $=1.04 \pm 0.06 C_{D}$ (canopy-scale), indicating that $C_{D}$ estimated by Eqn. 11 and $C_{D}$ measured on an individual plant were interchangeable. This indicated that the drag (energy loss) associated with shear generated in the spaces between plants was negligible. This supports the application of plant-scale drag for use in distributed drag models.

Figure 5. Comparison of canopy-scale $C_{D}$, determined from Eqn. 11, and plant-scale $C_{D}$, based on force measured on an individual plant within a canopy (from Xu \& Nepf, 2020). The horizontal error bars arise from the uncertainty of water surface slope. The vertical error bars are associated with replicate measurements of force on the individual plant. The dashed line represents the 1:1 line.

\subsection{Diffusivity in a Typha latifolia canopy}

The SSC profile was simulated using the RDM with a range of diffusivity scale factors in Eqn. 7, $\alpha_{z}=0.5$ to 4.0 , and these were compared to the measured profiles (Figure 6a and 6c). As $\alpha_{z}$ increased, the simulated SSC decreased near the bed and increased in upper canopy, consistent with an increase in vertical turbulent diffusion. The difference between simulated and measured SSC was quantified with the mean percentage error (Eqn. 6, inset graphs in Figure 6). The trend of MPE with $\alpha_{z}$ was similar for all cases (Figure S7 in Supporting Information), decreasing rapidly between $\alpha_{z}=0.5$ to 1 , and reaching a minimum error of $1.2 \%$ to $4.8 \%$ for $\alpha_{z}$ between 1.5 and 4 (Table 1). The best-fit $\alpha_{z}$ differed with water depth. For $H=20 \mathrm{~cm}$, best-fit $\alpha_{z}$ ranged from 1.5 to 2.5 , with mean $2.0 \pm 0.4$. For $H=30 \mathrm{~cm}$ and $35 \mathrm{~cm}$, best-fit $\alpha_{z}$ ranged from 2.5 to 4.0, with mean $3.1 \pm 0.5$. There was no dependence of $\alpha_{z}$ on velocity (Table 1), which was consistent with Tanino's description of $\alpha_{z}$ as a function of canopy morphology and the fact that no reconfiguration was observed (Section 2.3 in Tanino \& Nepf, 2008).

The profile of vertical diffusivity $D_{z}$ corresponding to the best-fit $\alpha_{z}$ is presented in Figures $6 \mathrm{~b}$ and $6 \mathrm{~d}$. The diffusivity in a bare channel (Eqn. 10) with the same channel velocity was included with a dashed curve, which illustrated the significant degree to which the canopy enhanced the vertical diffusivity. For example, in Cases 1.1 and 3.1, the depth-average $D_{z}$ with $T$. latifolia was 5 to 10 times higher than that for bare channel. The canopy also changed the shape of the diffusivity profile. The diffusivity was highest in the culm region near the bed, corresponding

This article is protected by copyright. All rights reserved. 
to the region of maximum turbulent kinetic energy $k_{t}$ and integral length-scale $l_{t}$ (Figure $4 \mathrm{e}$ and $4 \mathrm{f}$ ). However, it is worth noting that the comparison in the present study assumed the same velocity in the vegetated and bare channel, whereas in reality the velocity will be lower in the vegetation. For a fixed water surface slope driving flow into the vegetation, velocity decreases with increasing stem density. The decreasing velocity dominates the augmented turbulence generation (Eqn. 9), such that turbulence decreases with increasing stem density (see Figure 4 in Yang and Nepf, 2018), from which Eqn.7 predicts a decrease in vertical diffusivity with increasing stem density.

Figure 6. Subplots (a) and (c) compare measured equilibrium SSC profile (open circle) and RDM simulation (dashed lines, from blue to red $\alpha_{z}=0.5$ to 4). Concentration normalized by the depth-average $\langle C\rangle_{z}$. (a) Case $1.1: H=20 \mathrm{~cm}$, $U=7.6 \mathrm{~cm} / \mathrm{s}$, (c) Case 3.1: $H=35 \mathrm{~cm}, U=4.8 \mathrm{~cm} / \mathrm{s}$ (legend in subplot a). Inset graph shows mean percentage error (MPE) between measured and simulated concentration as a function of $\alpha_{z}$. Subplots (b) and (d) are vertical profiles of diffusivity using best-fit $\alpha_{z}$ in T. latifolia canopy (open triangle) and bare channel (Eqn. 10, dashed lines) for (b) Case 1.1 and (d) Case 3.1 (legend in subplot b).

To further explore the diffusivity model, the streamwise evolution of SSC profiles was simulated and compared to the measured concentration at $x=0.5,1.0,1.9,3.1 \mathrm{~m}$. (Figure S9 in Supporting Information). Because the evolving SSC profiles involved a wider range of sediment vertical distribution, it provided a more robust assessment of bestfit $\alpha_{z}$ (Table 4). For the smallest depth (occupied mostly by the culm), the best-fit alpha based on SSC spatial evolution was $\alpha_{z}=1.0 \pm 0.4$, which was smaller than that inferred from equilibrium SSC, $\alpha_{z}=2.0 \pm 0.4$. However, for the larger depths (which included both culm and leaves), the best-fit from SSC spatial evolution, $\alpha_{z}=2.8 \pm 0.6$, was the same within uncertainty to that based on the equilibrium profile, $\alpha_{z}=3.1 \pm 0.5$.

Table 4. Best-fit $\alpha_{z}$ based on spatial evolution and equilibrium SSC profile

\begin{tabular}{cccccc}
\hline Run & $\begin{array}{c}H \\
(\mathrm{~cm})\end{array}$ & $\begin{array}{c}\text { distance from } \\
\text { leading edge }(\mathrm{m})\end{array}$ & $\begin{array}{c}\text { Top of particle plume } \\
(\mathrm{cm})\end{array}$ & $\begin{array}{c}\text { Best-fit } \alpha_{z} \text { at } \\
\text { corresponding x }\end{array}$ & $\begin{array}{c}\text { Best-fit } \alpha_{z} \\
\text { at equilibrium }\end{array}$ \\
\hline 1.1 & 20 & $1.0,3.1$ & 13,20 & $0.5,1.5$ & 2.5 \\
1.2 & 20 & $0.5,1.0,1.9,3.1$ & $11,15,18,20$ & $0.5,1.0,1.0,1.5$ & 2.0 \\
2.2 & 30 & $0.5,1.0,1.9,3.1$ & $25,30,30,30$ & $3.0,3.0,2.0,2.0$ & 3.0 \\
3.2 & 35 & $1.0,3.1$ & 32,34 & $3.5,3.0$ & 3.5 \\
\hline
\end{tabular}

The fitted $\alpha_{z}$ values fell within expected values based on the modified Tanino model, suggesting that this model can predict $\alpha_{z}$ for natural canopies. Specifically, the culm region of the canopy (Figure 7a), has a geometry similar to a staggered array of vertical cylinders. For a staggered array of cylinders, previous studies have shown $\alpha_{z} \approx 0.25 \alpha_{y}$ 
(Nepf et al., 1997), and for $\phi=0.0057$ (Table 1) $\alpha_{y}=3.3$ (Figure 2), such that $\alpha_{z}=0.25 \alpha_{y}=0.83$. Considering only profiles for which the particle plume was isolated within the culm region (plume height $<20 \mathrm{~cm}$ in Table 4 ), the best-fit values yielded the average $\alpha_{z}=0.75 \pm 0.14$ (Table 4), which agreed with the model prediction. When the water depth was larger $(H=30$ and $35 \mathrm{~cm})$, the sediment interacted with the upper canopy of leaves with varied orientation, for which previous studies have suggested $D_{z} \approx D_{y}$ (Lightbody \& Nepf, 2006; Nepf, 1999). Then, from Figure 2, we predict $\alpha_{z}=\alpha_{y}=3.3$. Considering the profiles for which the sediment interacted with the upper canopy (plume height $>20 \mathrm{~cm}$ ), the average $\alpha_{z}=2.9 \pm 0.2$ (Table 4), which was close to the predicted value $\left(\alpha_{z}=3.3\right)$. This agreement supports the hypothesis in Lightbody and Nepf (2006) that leaves with varied orientation generate an isotropic turbulent diffusion $\left(D_{z} \approx D_{y}\right)$. Further, the best-fit $\alpha_{z}$ increased with increasing plume height, consistent with an increasing contribution of the leaf region (Figure 7c). These observations suggested that the diffusion scale factor had a dependence on water depth, due to the range of morphology included for different depths. The following values of $\alpha_{z}$, dependent on water depth, are recommended for the T. latifolia canopy (also dashed lines in Figure 7c).

$$
\alpha_{z}=\left\{\begin{array}{clr}
0.25 \alpha_{y}, & \multicolumn{1}{c}{H<15 \mathrm{~cm}} & (\text { culm) } \\
(0.08 H-0.9) \alpha_{y}, & 15 \mathrm{~cm} \leq H<25 \mathrm{~cm} & \text { (transtion) } \\
\alpha_{y} & H \geq 25 \mathrm{~cm} & \text { (leaves) }
\end{array}\right.
$$

The three regions (culm, transition, leaves) were distinguished by three linear regions within the profile of frontal area of T. latifolia (red lines in Figure 7b). To apply this profile to other canopies, one would need to identify the vertical extend of the culm-dominated and leaf-dominated regions based on plant morphology. Note that Eqn. 12 defines a constant value of $\alpha_{z}$ as a function of water depths $(H)$, but we also considered the impact of $\alpha_{z}$ variation over depth (z). However, this additional level of detail did not significantly impact the simulation (see Supporting Information, S10), indicating that a constant $\alpha_{z}=f(H)$ is adequate for representing the vertical variation in diffusivity (Eq. 7).

Figure 7. (a) Definition of morphology regions within a T. latifolia canopy. Near the bed, leaves are tightly clustered in culms, resembling vertical cylinders. Near the top of the canopy, leaves have varied orientation. (b) Vertical profile of $T$. latifolia frontal area per $\mathrm{cm}$ vertical interval, $A\left[\mathrm{~cm}^{2} / \mathrm{cm}\right]$, shown with black dots. Three regions were distinguished by linear regions within the frontal area profile, shown with red lines. (c) The vertical diffusion scale factor $\alpha_{z}$ varied with water depth. The dashed lines are Eqn. 12. The blue, gray, and red symbols are the best-fit $\alpha_{z}$ from RDM simulations with $H=20 \mathrm{~cm}, 30 \mathrm{~cm}$, and $35 \mathrm{~cm}$, respectively. The vertical position of each symbol corresponds to the top of the plume (i.e., Table 4), reflecting the depth over which the plume has been mixed, and thus the vertical domain over which diffusivity has acted on the plume.

\subsection{Adaption time of SSC in Typha latifolia canopy}

When water carrying suspended sediment enters a marsh, the SSC profile adjusts to the new vegetated flow condition. It is useful to know the time-scale for this adjustment, called the adaption time, as this predicts the distance from the This article is protected by copyright. All rights reserved. 
marsh edge that a new equilibrium SSC profile will evolve, $X_{a}=U T_{a}$. In addition, this provides guidance for choosing the run time for numerical simulations. The adaptation time was determined from the RDM using the mean percentage error (MPE, Eqn. 6) in the concentration profile. At each time step the MPE of SSC at the current $i$ and previous $i-1$ time step was calculated. When MPE was less than 2\%, the SSC was assumed to reach the equilibrium state and this defined the adaptation time, $T_{a}$.

For channels without vegetation and fine sediment (small sediment Peclet Number, $P_{e}=w_{S} H / D_{z}<1$ ), previous studies have found $T_{a}$ scales with the diffusivity and water depth (Chatwin, 1972; Fischer, 1973, Prandle, 1997; Pritchard, 2006),

$$
T_{a}=\beta \frac{H^{2}}{\left\langle D_{z}\right\rangle_{z}}
$$

in which $\left\langle D_{z}\right\rangle_{z}$ is the depth-averaged vertical diffusivity and $\beta$ is a scale coefficient. The RDM simulations indicated the same scaling also applied within the T. latifolia canopy (Figure 8), with $\beta=0.41 \pm 0.09$, which was consistent with the value of $\beta$ suggested in Fischer (1973). For coarse particles (large $P_{e}$ ), the adaption time-scale would be set by the settling time, $T_{a} \sim \mathrm{H} / w_{s}$ (Pritchard, 2006), since the gravity of particle would dominate the adaption process.

Figure 8. Comparison between adaptation time $T_{a}$ and diffusion time-scale $H^{2} /\left\langle D_{z}\right\rangle_{z}$. Blue to red colors represent increasing velocity $U$. The vertical error bars reflect the standard error among $10 \mathrm{RDM}$ simulation. The horizontal error bars arise from the spatial variation in $\left\langle D_{z}\right\rangle_{z}$ The dashed line is the fitting curve $T_{a}=0.41 H^{2} /\left\langle D_{z}\right\rangle_{z}$.

\subsection{Model application}

Together with Xu and Nepf (2020), the present study provides a way to model vertical diffusivity within a canopy of emergent vegetation. This could be used to estimate the adaptation time-scale (Eqn. 13) and associated adaptation distance, which can be used to predict or interpret deposition patterns within marshes. The diffusivity can also be used within a RDM or a field-scale simulation tool (e.g., Delft-3D) to predict the fate of suspended sediment within a marsh. The model requires a characterization of the plant frontal area profile, $A(\mathrm{z})$ (e.g., see image analysis described in Figure 1 of Xu and Nepf 2020, and Figure 7), and the plant area density $(m)$, culm diameter $(d)$ and leaf width $(w)$. These plant geometric parameters defined the vertical profiles of $a=m A$ and $l_{t}$ (as in Eqn. 8). The vertical profile of velocity, $\langle\bar{u}\rangle$ can be inferred from Eqn. 11, or from the hydrodynamic simulation. Eqn. 9 estimates the turbulent kinetic energy, $k_{t}$. The diffusivity scale constants $\alpha_{y}$ and $\alpha_{z}$ are estimated from the solid volume fraction (Figure 2) and water depth (Eqn. 12). The vertical profile of vertical diffusivity, $D_{z}$, is then estimated from Eqn. 7. We note that, at the field scale the plant geometric parameters $(A, m, d$, and $w)$ can vary in the horizontal 
plane. Because velocity and turbulence adjust over fairly short distances (a few water depths) within emergent canopies (Figure 4 in Xu and Nepf 2020), the turbulent diffusivity (Eqn. 7) will also adjust quickly. This means that the model for turbulent diffusivity described in the present paper could be used to model spatial variation in diffusivity across scales of canopy variation, if the spatial distributions of $A, m, d$, and $w$ are known.

\section{Conclusion}

The presence of vegetation alters the vertical structure of the mean and turbulent velocity, and these changes impact the vertical diffusivity and suspended sediment profiles. Compared to conditions without vegetation, but the same velocity, the vertically diffusivity within a T. latifolia canopy was both larger and exhibited a vertical variation correlated with plant morphology, both of which can be attributed to vegetation-generated turbulence. Specifically, vegetated-generated diffusivity was higher in the culm region near the bed, and decreased in the upper canopy, dominated by distributed leaves. Correlated to this, the SSC profile in the lower region of the canopy was nearly uniform, while in upper region the concentration decreased with distance from the bed. Drawing on existing models for stem-generated turbulence, a model for vertical diffusivity was validated with tracer data within cylinder arrays and then modified to reflect the specific morphology of the T. latifolia canopy. RDM simulations using the modified diffusivity model produced good agreement with the measured suspended sediment concentration. The new diffusivity model can be used to improve prediction of sediment fate in marsh systems.

\section{Acknowledgements}

This study received support from Gulf Research Program, Research Practice Grant. Any opinions, findings, and conclusions in this paper are those of the author(s) and do not necessarily reflect the views of the funding agencies. Yuan Xu was supported by the National Natural Science Foundation of China (51879138) and the China Scholarship Council. We thank Elizabeth Follett for her great assistance with numerical model. We thank Rachel Schaefer for her great assistance with the experiments and Danxun Li for his insightful discussions. The data used to generate key figures in this paper are available through Figshare at this site (https://doi.org/10.6084/m9.figshare.14123651).

\section{Reference}

Absi, R. (2010). Concentration profiles for fine and coarse sediments suspended by waves over ripples: An analytical study with the 1-DV gradient diffusion model. Advances in Water Resources, 33(4), 411-418. https://doi.org/10.1016/j.advwatres.2010.01.006

Barbier, E. B., Hacker, S. D., Kennedy, C., Koch, E. W., Stier, A. C., \& Silliman, B. R. (2011). The value of This article is protected by copyright. All rights reserved. 
estuarine and coastal ecosystem services. Ecological Monographs, 81(2), 169-193.

https://doi.org/10.1890/10-1510.1

Cellino, M. (1998). Experimental study of suspension flow in open channels (PhD thesis). Lausanne, CHE: Ecole Polytechnique Fédérale de Lausanne. https://doi.org/10.5075/epfl-thesis-1824

Chatwin, P. C. (1972). The cumulants of the distribution of concentration of a solute dispersing in solvent flowing through a tube. Journal of Fluid Mechanics, 51(1), 63-67. https://doi.org/10.1017/S0022112072001077

Coleman, N. L. (1986). Effects of Suspended Sediment on the Open-Channel Velocity Distribution. Water Resources Research, 22(10), 1377-1384. https://doi.org/10.1029/WR022i010p01377

Costanza, R., d'Arge, R., de Groot, R., Farber, S., Grasso, M., Hannon, B., et al. (1997). The value of the world's ecosystem services and natural capital. Nature, 387(6630), 253-260. https://doi.org/10.1038/387253a0

Durbin, P. A. (1983). Stochastic differential equations and turbulent dispersion. NASA reference publication 1103. https://ntrs.nasa.gov/search.jsp?R=19830014275

Etminan, V., Ghisalberti, M., \& Lowe, R. J. (2018). Predicting Bed Shear Stresses in Vegetated Channels. Water Resources Research, 54(11), 9187-9206. https://doi.org/10.1029/2018WR022811

Fauria, K. E., Kerwin, R. E., Nover, D., \& Schladow, S. G. (2015). Suspended particle capture by synthetic vegetation in a laboratory flume. Water Resources Research, 51(11), 9112-9126. https://doi.org/10.1002/2014WR016481

Ferguson, R. I., \& Church, M. (2004). A Simple Universal Equation for Grain Settling Velocity. Journal of Sedimentary Research, 74(6), 933-937. https://doi.org/10.1306/051204740933

Fischer, H. B. (1973). Longitudinal Dispersion and Turbulent Mixing in Open-Channel Flow. Annual Review of Fluid Mechanics, 5(1), 59-78. https://doi.org/10.1146/annurev.f1.05.010173.000423

Follett, E., Chamecki, M., \& Nepf, H. (2016). Evaluation of a random displacement model for predicting particle escape from canopies using a simple eddy diffusivity model. Agricultural and Forest Meteorology, 224, 40-48. https://doi.org/10.1016/j.agrformet.2016.04.004

Follett, E., \& Nepf, H. (2018). Particle Retention in a Submerged Meadow and Its Variation Near the Leading Edge. Estuaries and Coasts, 41(3), 724-733. https://doi.org/10.1007/s12237-017-0305-3

Fourqurean, J. W., Duarte, C. M., Kennedy, H., Marbà, N., Holmer, M., Mateo, M. A., et al. (2012). Seagrass ecosystems as a globally significant carbon stock. Nature Geoscience, 5(7), 505-509.

https://doi.org/10.1038/ngeo1477

Gardiner, C. (2009). Stochastic methods (Vol. 4). Berlin: Springer.

Goring, D. G., \& Nikora, V. I. (2002). Despiking Acoustic Doppler Velocimeter Data. Journal of Hydraulic Engineering, 128(1), 117-126. https://doi.org/10.1061/(ASCE)0733-9429(2002)128:1(117)

Huai, W., Yang, L., Wang, W.-J., Guo, Y., Wang, T., \& Cheng, Y. (2019). Predicting the vertical low suspended sediment concentration in vegetated flow using a random displacement model. Journal of Hydrology, 578, 124101. https://doi.org/10.1016/j.jhydrol.2019.124101

Israelsson, P. H., Kim, Y. D., \& Adams, E. E. (2006). A comparison of three Lagrangian approaches for extending near field mixing calculations. Environmental Modelling \& Software, 21(12), 1631-1649. https://doi.org/10.1016/j.envsoft.2005.07.008

Jiménez, J. (2012). Cascades in Wall-Bounded Turbulence. Annual Review of Fluid Mechanics, 44(1), 27-45. https://doi.org/10.1146/annurev-fluid-120710-101039

Kemp, J. L., Harper, D. M., \& Crosa, G. A. (2000). The habitat-scale ecohydraulics of rivers. Ecological Engineering, 16(1), 17-29. https://doi.org/10.1016/S0925-8574(00)00073-2

Kretz, L., Seele, C., van der Plas, F., Weigelt, A., \& Wirth, C. (2020). Leaf area and pubescence drive sedimentation on leaf surfaces during flooding. Oecologia, 193(3), 535-545. https://doi.org/10.1007/s00442-020-04664-2

Leonard, L. A., \& Luther, M. E. (1995). Flow hydrodynamics in tidal marsh canopies. Limnology and Oceanography, 40(8), 1474-1484. https://doi.org/10.4319/lo.1995.40.8.1474

Li, Y., Xie, L., \& Su, T. C. (2020). Profile of Suspended Sediment Concentration in Submerged Vegetated Shallow

This article is protected by copyright. All rights reserved. 
Water Flow. Water Resources Research, 56(4), e2019WR025551. https://doi.org/10.1029/2019WR025551

Lightbody, A.F. (2004). Field and laboratory observations of small-scale dispersion in wetlands (MS thesis). MA, USA: Massachusetts Institute of Technology.

Lightbody, A. F., \& Nepf, H. M. (2006). Prediction of velocity profiles and longitudinal dispersion in salt marsh vegetation. Limnology and Oceanography, 51(1), 218-228. https://doi.org/10.4319/lo.2006.51.1.0218

Liu, J., Zhang, Z., Yu, Z., Liang, Y., Li, X., \& Ren, L. (2017). The Structure and Flexural Properties of Typha Leaves. Applied Bionics and Biomechanics, 2017, 1-9. https://doi.org/10.1155/2017/1249870

Lu, S. Q. (2008). Experimental study on suspended sediment distribution in flow with rigid vegetation ( $\mathrm{PhD}$ thesis). Jiangsu, CN: Hohai University (in Chinese).

Minderhoud, P. S. J., Coumou, L., Erkens, G., Middelkoop, H., \& Stouthamer, E. (2019). Mekong delta much lower than previously assumed in sea-level rise impact assessments. Nature Communications, 10(1), 3847. https://doi.org/10.1038/s41467-019-11602-1

Murphy, E. (2006). Longitudinal Dispersion in Vegetated Flow (MS thesis). MA, USA: Massachusetts Institute of Technology.

Naden, P., Rameshwaran, P., Mountford, O., \& Robertson, C. (2006). The influence of macrophyte growth, typical of eutrophic conditions, on river flow velocities and turbulence production. Hydrological Processes, 20(18), 3915-3938. https://doi.org/10.1002/hyp.6165

Nepf, H. M. (1999). Drag, turbulence, and diffusion in flow through emergent vegetation. Water Resources Research, 35(2), 479-489. https://doi.org/10.1029/1998WR900069

Nepf, H. M. (2012). Flow and Transport in Regions with Aquatic Vegetation. Annual Review of Fluid Mechanics, 44(1), 123-142. https://doi.org/10.1146/annurev-fluid-120710-101048

Nepf, H. M., Sullivan, J. A., \& Zavistoski, R. A. (1997). A model for diffusion within emergent vegetation. Limnology and Oceanography, 42(8), 1735-1745. https://doi.org/10.4319/lo.1997.42.8.1735

Nittrouer, J. A., Best, J. L., Brantley, C., Cash, R. W., Czapiga, M., Kumar, P., \& Parker, G. (2012). Mitigating land loss in coastal Louisiana by controlled diversion of Mississippi River sand. Nature Geoscience, 5(8), 534537. https://doi.org/10.1038/ngeo1525

Prandle, D. (1997). Tidal Characteristics of Suspended Sediment Concentrations. Journal of Hydraulic Engineering, 123(4), 341-350. https://doi.org/10.1061/(ASCE)0733-9429(1997)123:4(341)

Pritchard, D. (2006). Rate of Deposition of Fine Sediment from Suspension. Journal of Hydraulic Engineering, 132(5), 533-536. https://doi.org/10.1061/(ASCE)0733-9429(2006)132:5(533)

Purich, A. (2006). The Capture of Suspended Particles by Aquatic Vegetation (PhD thesis). Perth, AUS: University of Western Australia.

Rouse, H. (1937). Modern conceptions of the mechanics of fluid turbulence. Trans ASCE, 102, 463-505.

Tanino, Y. (2008). Flow and solute transport in random cylinder arrays: A model for emergent aquatic plant canopies (PhD thesis). MA, USA: Massachusetts Institute of Technology.

Tanino, Y., \& Nepf, H. M. (2008). Lateral dispersion in random cylinder arrays at high Reynolds number. Journal of Fluid Mechanics, 600, 339-371. https://doi.org/10.1017/S0022112008000505

Tarrell, A. E. (1997). A field investigation of diffusion within a submerged plant canopy (MS thesis). MA, USA: Massachusetts Institute of Technology and Woods Hole Oceanographic Institution. https://doi.org/10.1575/1912/5667

Taylor, G. I. (1953). Dispersion of soluble matter in solvent flowing slowly through a tube. Proceedings of the Royal Society of London. Series A. Mathematical and Physical Sciences, 219(1137), 186-203. https://doi.org/10.1098/rspa.1953.0139

Tinoco, R. O. (2011). An experimental investigation of drag and the turbulent flow structure in simulated and real aquatic vegetation ( $\mathrm{PhD}$ thesis). NY, USA: Cornell University.

Tsai, C. W., Hung, S. Y., \& Wu, T.-H. (2020). Stochastic sediment transport: anomalous diffusions and random movement. Stochastic Environmental Research and Risk Assessment, 34(2), 397-413.

This article is protected by copyright. All rights reserved. 
https://doi.org/10.1007/s00477-020-01775-3

Tseng, C., \& Tinoco, R. O. (2020). A Two $\square$ Layer Turbulence $\square$ based Model to Predict Suspended Sediment Concentration in Flows with Aquatic Vegetation. Geophysical Research Letters.

https://doi.org/10.1029/2020GL091255

Wilson, J. D., \& Yee, E. (2007). A critical examination of the random displacement model of turbulent dispersion. Boundary-Layer Meteorology, 125(3), 399-416. https://doi.org/10.1007/s10546-007-9201-x

Wingenroth, J., Yee, C., Nghiem, J., \& Larsen, L. (2021). Effects of Stem Density and Reynolds Number on Fine Sediment Interception by Emergent Vegetation. Geosciences, 11(3), 136.

https://doi.org/10.3390/geosciences11030136

$\mathrm{Xu}, \mathrm{Y} .$, \& Nepf, H. (2020). Measured and Predicted Turbulent Kinetic Energy in Flow Through Emergent Vegetation With Real Plant Morphology. Water Resources Research, 56(12), e2020WR027892. https://doi.org/10.1029/2020WR027892

Yang, J. Q., \& Nepf, H. M. (2018). A Turbulence $\square$ Based Bed $\square$ Load Transport Model for Bare and Vegetated Channels. Geophysical Research Letters, 45(19), 10,428-10,436. https://doi.org/10.1029/2018GL079319

Zhang, Y., Lai, X., Ma, J., Zhang, Q., Yu, R., Yao, X., \& Deng, H. (2021). Field study on flow structures within aquatic vegetation under combined currents and small $\square$ scale waves. Hydrological Processes, 35(4). https://doi.org/10.1002/hyp.14121

This article is protected by copyright. All rights reserved. 

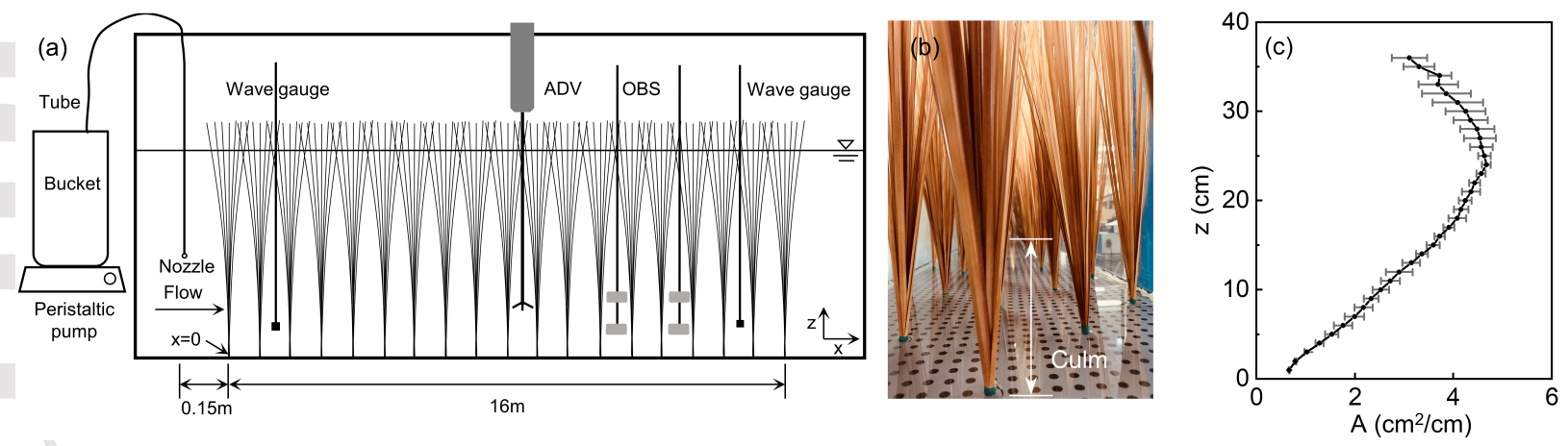

This article is protected by copyright. All rights reserved. 


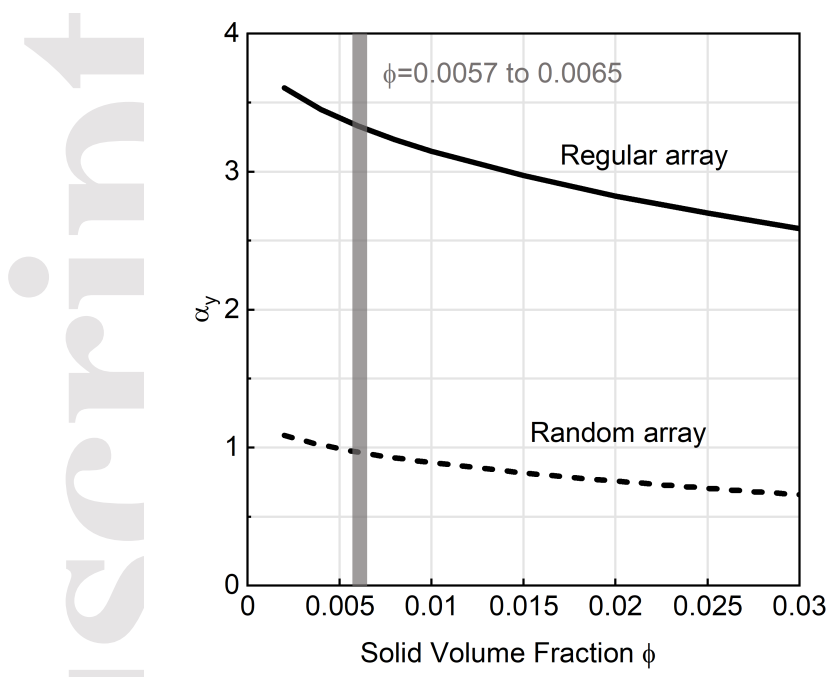

This article is protected by copyright. All rights reserved. 

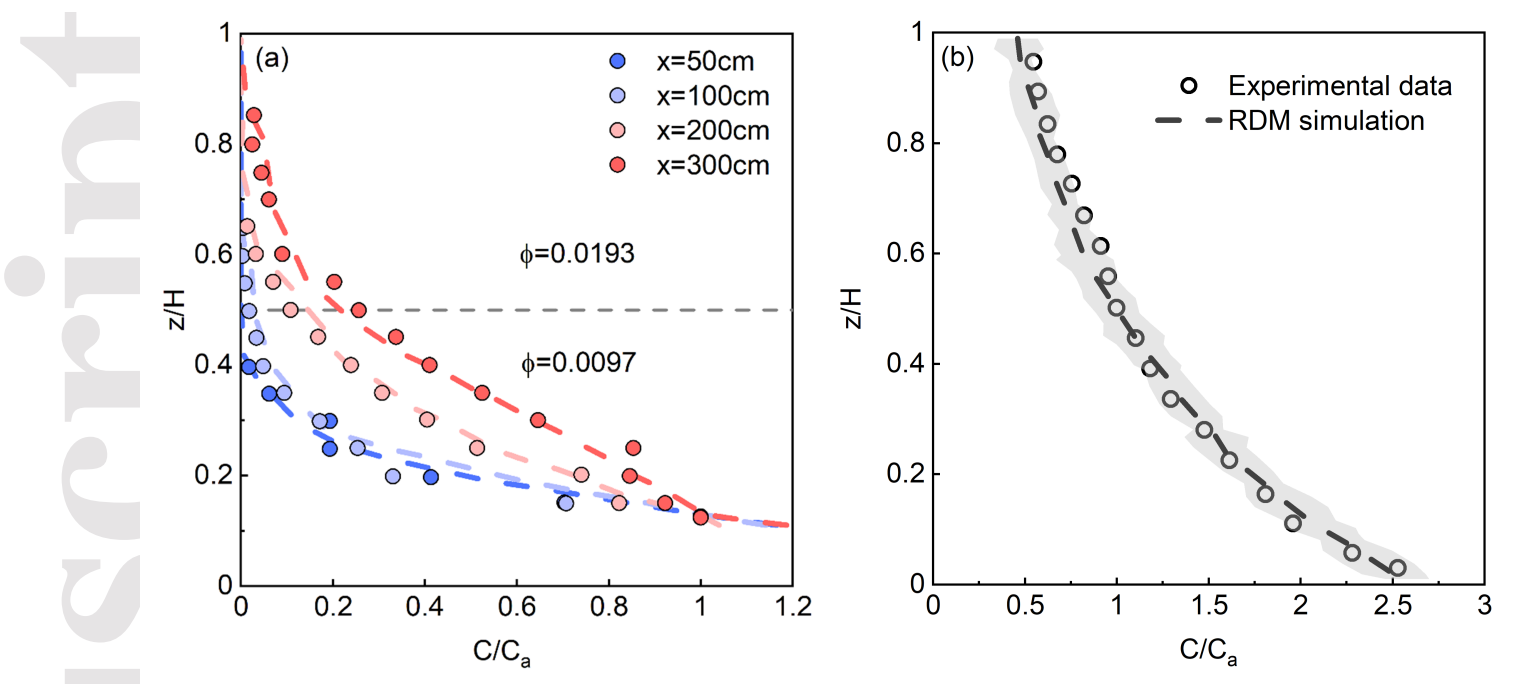

This article is protected by copyright. All rights reserved. 

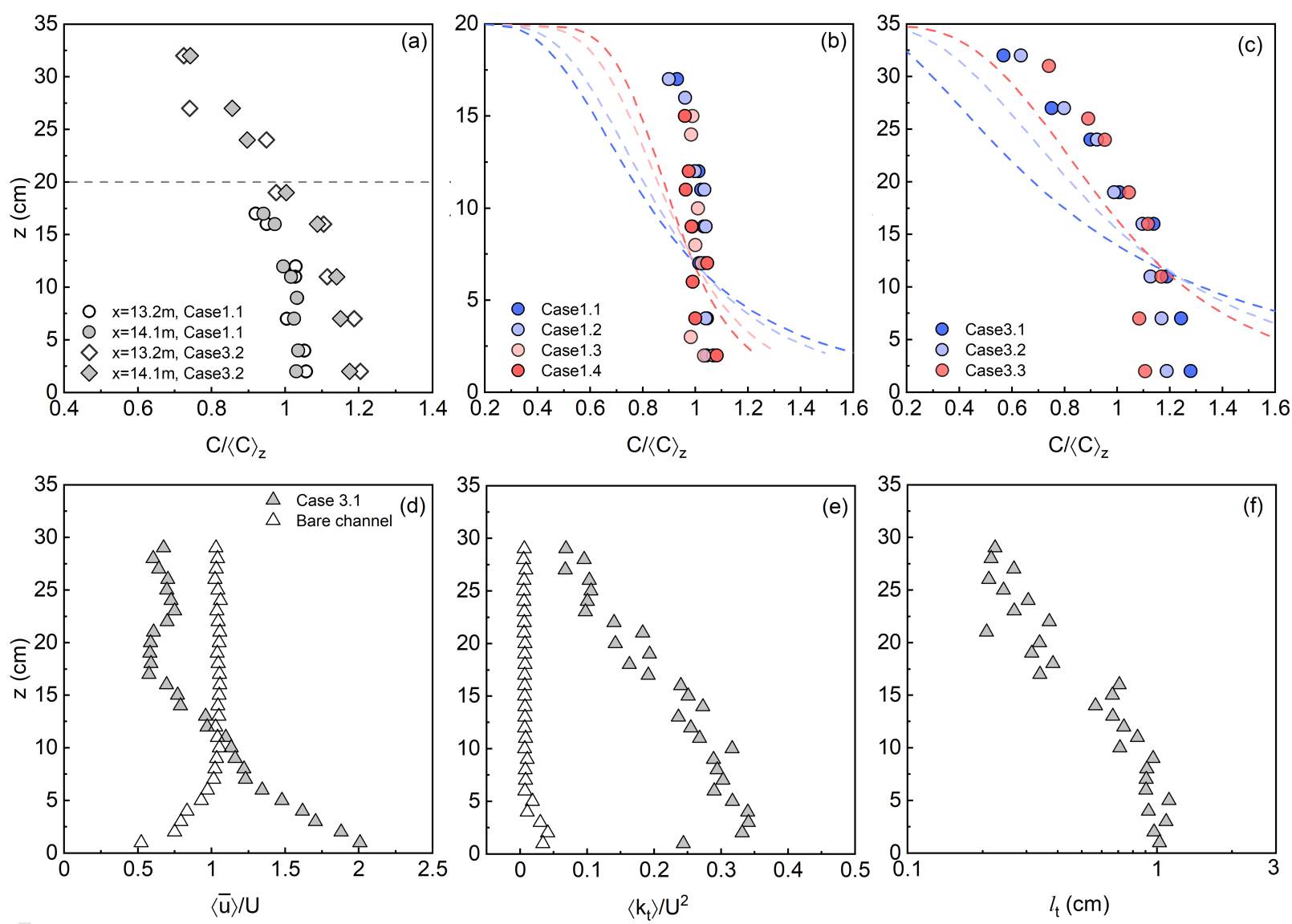

This article is protected by copyright. All rights reserved. 


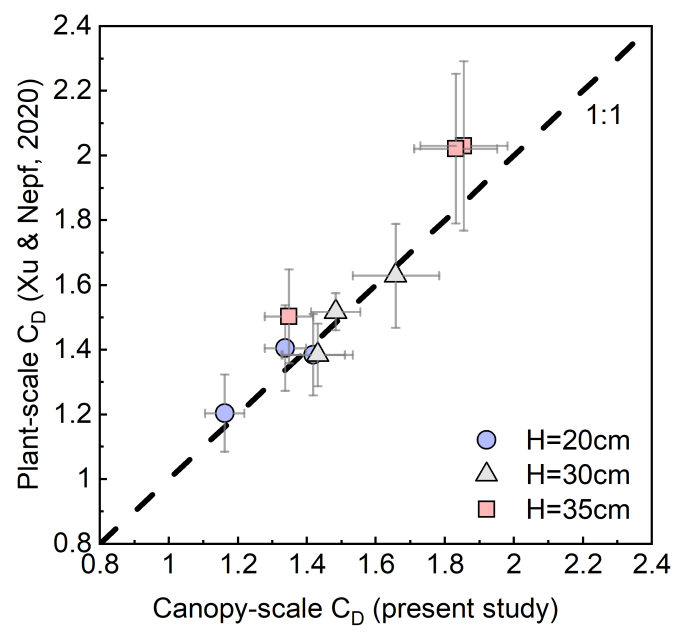

This article is protected by copyright. All rights reserved. 

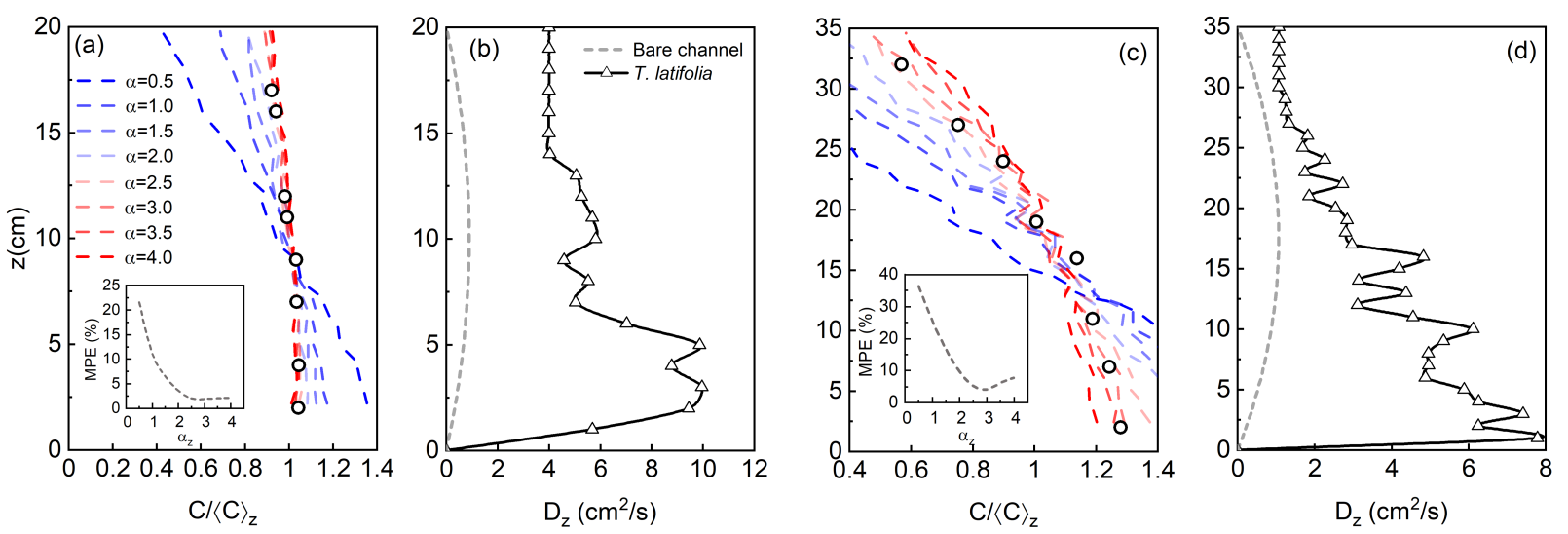

This article is protected by copyright. All rights reserved. 

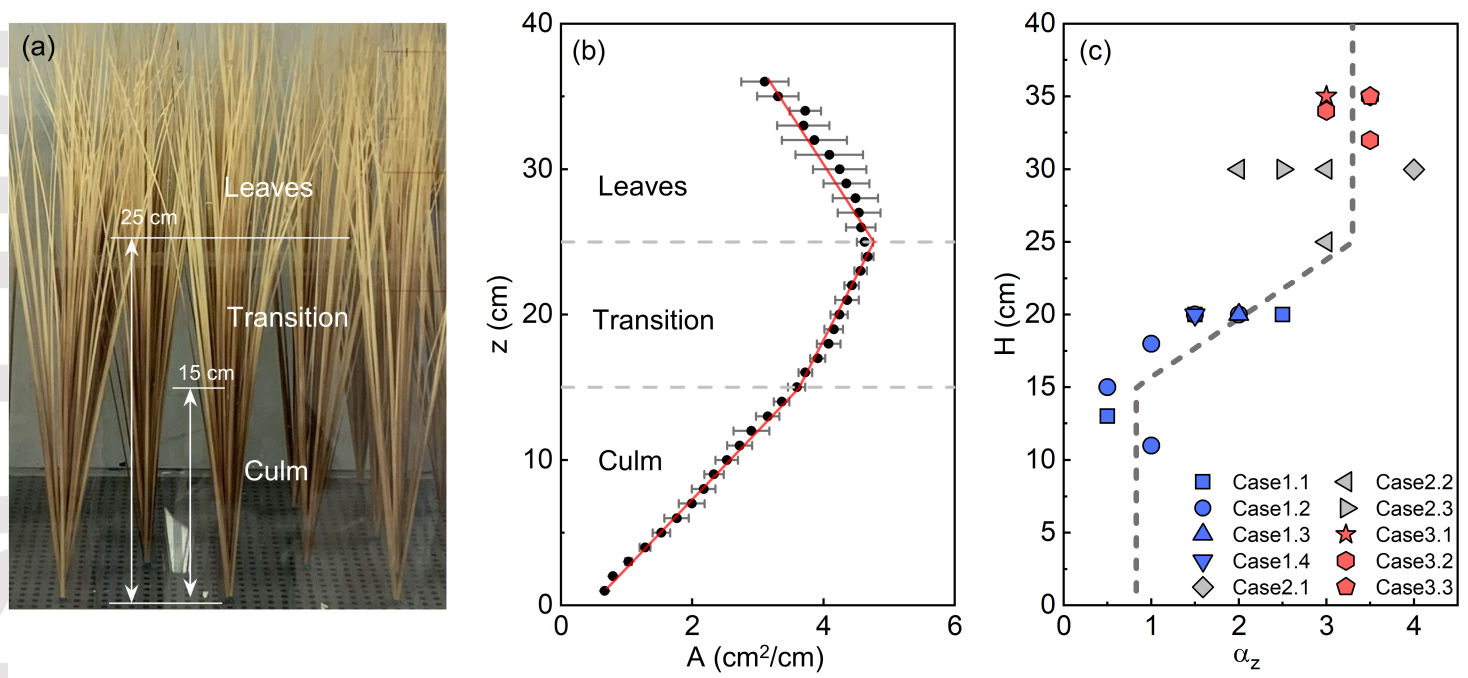

This article is protected by copyright. All rights reserved. 


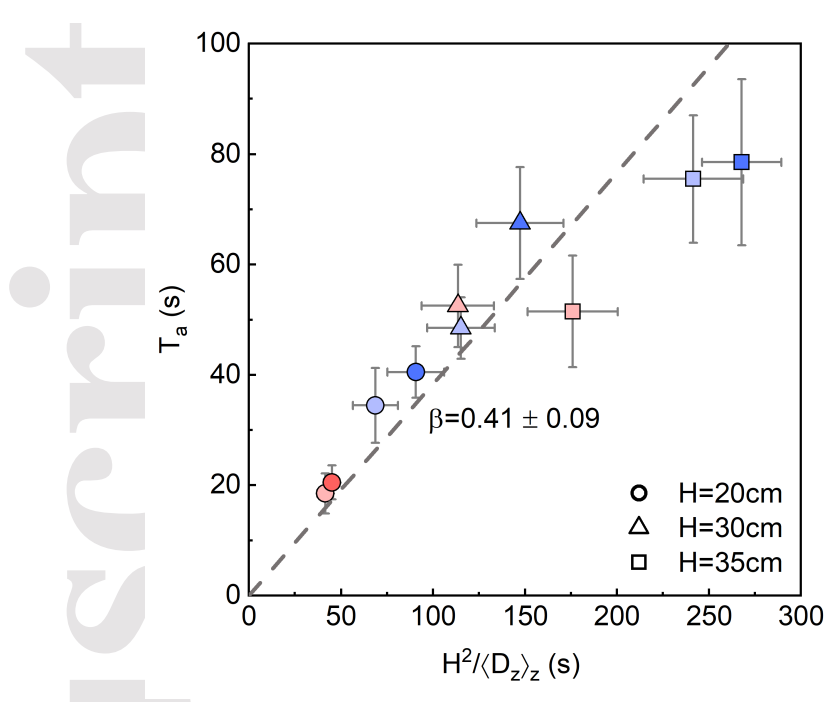

This article is protected by copyright. All rights reserved. 